\title{
İslam Dininin Suça Bakıșı ve Suçu Önlemeye Yönelik Yaklașımları Üzerine Bir Analiz
}

\author{
İsmail GÜLLÜ $\quad$ Muhammet Ali CAN ${ }^{2}$ \\ ${ }^{1}$ Karamanoğlu Mehmetbey Üniversitesi, Sosyoloji Bölümü, Karaman \\ ${ }^{2}$ Necmettin Erbakan Üniversitesi, Sosyal Bilimler Enstitüsü, Konya.
}

\begin{abstract}
Özet
Bu bildiri, genel bağlamda, dinin suça yaklaşımını, özelde ise İslam Dininin suç olgusunu nasıl ele aldığı ve suçu önlemeye yönelik teorik ve toplumsal mekanizmaların işlevi üzerinde durmaktadır. Suçun mahiyetini, İslam dininin suç tanımını, suç ile sosyal psikoloji arasındaki ilişki hakkında giriş mahiyetinde bilgi verilmiştir. İbadetlerin suçları önleme açısından nasıl bir işlev gördüğ̈̈ açıklanmıștır. Suçu önlemeye yönelik toplumların sosyolojik yapıları üzerinde dinin müdahalesi hakkında bilgi verilmiştir.

Anahtar kelimeler: Din, suç, toplumsal değişme
\end{abstract}

\section{An Analysis On The Outlook Of Islam Religion On Crime And Its' Approaches To Prevent Crime}

\footnotetext{
Abstract

This paper puts emphasis on the religion's approach to crime in general and in particular, how religion Islam deals with crime and theoretical and social mechanisms' function on prevention of crime. Introductory information is given about nature of crime, Islam's definiton of crime, relationship between crime and social psychology. How worships function in terms of preventing crime is explained. The information about societies' social structure directed to prevent crime is given.

Keywords: Religion, crime, social change
}

\section{Giriş}

Din olgusu, diğer toplumsal olay ve olgularla yakından ve karşılıklı ilişski içerisindedir. Din-suç ilişkisinin toplumsal boyutları üzerine araştırmalar, Durkheim'den bu güne daha çok toplumsal uyum merkezli yapılmıştır. Bu bildirinin konusu, İslam dininin suç olgusuna bakış açısını etimolojik ve teorik düzlemde ele almak ve İslam geleneği içinde suçu önlemeye ve azaltmaya yönelik ayet, hadis ve yaklaşımlardan hareketle bir analiz ortaya koymaktır. Bu bildiride "İslam dinini teorik ve pratik birikimi içerisinde günümüz Türk toplumunda suçun önlenmesine katkı sağlayacak unsurlar mümkün mü dür? sorusuna cevap aramak ve tartışmaya açmak hedeflenmiştir.

Batı ülkelerinde de Türkiye' de de suç ve dindarlık arasında bir ilişkinin olup olmadığına dair birçok araştırma yapılmıştır. Büyük çoğunluğu Müslüman olan Türkiye'nin geleneksel yapısı içerisinde ortaya çıkan suç gibi sosyal problemlerin bir çoğu, dini ve kültürel kodları ve uzantıları da içeren konulardır. $\mathrm{Bu}$ yönü ile sempozyumun konusu olan suç olgusunun Türk toplumunun zihinsel ve inançsal kod dünyası içindeki temellerini şekillendiren ayet, hadis, fetva, uygulama vb. temel bilgi formları üzerinde durulacaktır.

Kavramsal ve etimolojik bir analizden sonra İslam dinin temel kaynakları olarak kabul edilen Kuran ve Hadislerde suçun ele alınış şekilleri ve suçu önlemeye yönelik dini yaklaşımların neler olduğu üzerinde durulacaktır. Bu analizlerden hareketle günümüz Türk toplumunda suç olarak kabul edilen davranış biçimleri ve yaşam formları ile bu bilgi ve rivayetlerin ilişkisi/etkisi üzerine yoğunlaşılacaktır.
Etimolojik olarak analiz edildiğinde İslam dini terminolojisinde suç kavramının Cürüm (suç), Zenb (suç), ism (suç), hata' (hata), günah (suç), haram (yasak), nehy (yasak), ma'siye (isyan), isyan gibi kavramlar kullanılarak ifade edildiği görülmektedir. Bu kelimelerin hepsi İslam'ın gelişinden önce orta Arabistan'da kullanılmaktaydı. İslam'ın gelişi ile birlikte haram kelimesi Arap toplumunda dini 1st1lah haline geldi. Günah kelimesi ise Farsça ile Türkçe konuşan toplumlarda dini 1stılah haline gelmiştir. Din ile alakası olmayan suçlarda haram ile günah kelimeleri artık kullanılmamaktadır.

Suçun önlenmesi veya azaltılması sadece hukuk ile veya kolluk kuvvetlerinin çalışmaları ile sağlanabilecek bir olgu değildir. İnsanın duygu, düşünce ve inançları da bu anlamda söz konusu sürecin içinde olan boyutlardır. Dini ve ahlaki değerler bireyin suça yönelmesini engelleyici bir rol oynayabilmektedir.

Haram, günah, ayıp gibi kavramlar ile ifade edilen "haramlar; farz, vacip vb. kavramlar ile ifade edilen "emirler", insanın yaratılıştan potansiyel olarak var olan bir takım olumsuz özelliklerini azaltıcı, hatta düzeltici bir mahiyettedir. Ahiret ve melek inancı insanın bu dünyadaki yaşam şeklini diğer insanlarla ve toplum hayatındaki konumunu kontrol etmeyi zorunlu kılmaktadır. İnsanın akıl, vicdan, ruh ve beden gibi bir çok özellik ve boyutunun olması ve bunların birbiri ilişki içinde olması meseleyi monolitik (tek tip) bir yaklaşımdan çok multi-disipliner bir yaklaşımla ele almayı zorunlu kılmaktadır. 


\section{Dinlerde Suç}

İlk insan Hz. Adem'in yenmesi yasak olan meyveyi yemesi ile insanoğlunun ilk zamanlardan beri suç işlediği beri bilinmektedir. Habil ile Kabil arasındaki ilişkide meydana gelen suçlardan günümüze kadar insanoğlunun suç işlediği semavi dinlerin kutsal kitaplarında da konu edilmiştir (Tevrat, Yaratılış IV, 1-5). Hristiyanlıkta ise insanların tamamı doğuştan suçlu kabul edilir ve vaftiz ayini ile bu günahlardan arınırlar. İslam'da ise bütün insanlar doğuştan suçsuz kabul edilir. Hayatı boyunca yapmış olduğu hatalar nedeni ile suç işlerler.

\section{3. İslam Dini Açısından Suçun Mahiyeti}

Suçun önlenmesi konusuna geçmeden önce İslam'ın suça bakış açısını analiz etmek yararlı olacaktır. Hristiyanlıktan farklı olarak İslam dininde insanların doğuştan suçsuz ve masum olduğu kabul edilmektedir. Suçun sonradan arizi bir durum olduğu, yani bireyin içinde bulunduğu toplumsal, ekonomik, kültürel ve ailevî faktörlerin etkisiyle yöneldiği bir durum olarak kabul edilmektedir.

İslam dininde yapılan hatalar art niyetli (su-i niyet) olan ve art niyetli olmayan (hüsn-i niyet) şeklinde ikili bir perspektifle ele alınmaktadır. İslam'da art niyet ile yapılmayan hatalar suç kapsamına alınmamaktadır. Burada esas alınan şey yapılan fiilden ziyade fiilin niyetidir. Zira Peygamber Efendimizin uygulamalarında iyi niyet ile yapılmış olan hataların suç olarak kabul edilmediği bazı örneklerde görülmektedir. Buna bir örnek olarak Üsame b. Zeyd'in durumu gösterilebilir: Sahabeden Üsame b. Zeyd, yorum hatası ile savaşta düşman ordusundan öldürmüş olduğu kişi nedeniyle Peygamber Efendimiz tarafından sitem almış, ancak yaptığı hata suç kapsamında değerlendirilmemiş ve herhangi bir cezâî müeyyide uygulanmamıştır. Bu bağlamda Peygamber Efendimiz kişinin niyetinin sorgulanması yerine eylem ve beyana dayalı olarak değerlendirme yapmanın gerekliliğini ifade etmiştir.

$\mathrm{Bu}$ örnekte açıkça görüyoruz ki bir hatanın hukuki bir suç olarak kabul edilebilmesi için, hatayı yapan kişinin amacının da kötü olması gerekmektedir. Dolayısıyla bir hata art niyet ile yapılmış ise, o zaman suç kategorisine dahil edilmektedir. Aksi takdirde hatalı eylem iyi niyet ile yapılmış ise suç kategorisine dahil edilmemektedir. Bunu başka örneklerle de desteklemek mümkündür.

İslam dini içinde önemli kabul edilen zamanlardan biri olan ve af anlamına gelen Beraat gecesidir. Bütün bu bilgiler değerlendirildiğinde İslam'ın suç işlemiş insanlara yönelik bir "rehabilitasyon" (yeniden uyum sağlama) sürecine vurgu yaptığı görülmektedir.

İslam dinindeki suçla alakalı kavramsal çerçevenin en önemli boyutlarından birisi de suçun bireyler arası, yani toplumsal düzlemde "kul hakkı" kavramı ile ifade edilen şeklidir. Bireyle Allah (cc) arasında gerçekleştiği kabul edilen suçların affedilmesi teorik olarak sadece Allah ile kul arasında bir husus iken, bireyler arası işlenen suçlarda suçtan etkilenen kişilerin affetmesi esastır. Bundan dolayıdır ki dinin önemli olduğu kişi ve toplumlar için kul hakkı, suç işlemeyi yavaşlatıcı önemli bir mekanizma olarak değerlendirilebilir. Bu konuda bir diğer yaklaşım da, İslam Dininde suçun “Allah'ın hakkının ihlâli" olduğu ve işlenen suçun bireysel yönüne ilave olarak ilahî bir boyutun daha sürecin bir parçası olduğu görüşüdür (Halife, 1994: 17).

İslam dininde suçu işleyen kişinin işlediği suçun sorumluluğunun kabulü, suçlular arası dayanışmayı önleyici bir yaklaşım olarak değerlendirilebilir. "Hiçbir kimse, başkasının günahını yüklenmez (Zümer Suresi/7) . Bu anlamda örgütlü suçların önlenmesi için suçun bireyselliği düşüncesine vurgu yapan bu ayetin ortaya koyduğu yaklaşım, işlevsel bir yaklaşım olarak görülebilir. Çünkü kişi bir suçu tek başına değil de çevresindekilerle birlikte işlemesi durumunda kendisini suçlu hissetmemektedir. Örneğin hiçbir kimsenin rüşvet vermediği bir ortamda rüşvet veren kişi suçluluk psikolojisine girmektedir. Ancak çevresinde birçok kimsenin rüşvet verdiği ortamda rüşvet veren kişiler daha az suçluluk duygularına sahip olmaktadır. İslam'da her bireyin işlemiş olduğu suçtan kendisinin sorumlu olduğu Kuran-1 Kerim'de altı kez vurgulanarak bu durum engellenmeye çalışılmıştır.

Kul hakkı ile ilgili dikkat çekici bir diğer hadis de kaynaklarda şu şekilde geçmektedir:

"Kim bir kul hakkl yemişse derhal o kardeși ile helalleşsin. Çünkü (klyamet günü) dirhem de geçmez dinar da. Böyle olunca o (hak yiyen) kişinin sevaplar alınır o adama yüklenir. Eğer sevapları yoksa o hakkını yediği adamın günahları buna yüklenir." (Buhari, Rikak, 48).

Bireyin Allah'a karşı işlemiş olduğu suçlardan af dilemesi durumunda, kendisinin af olunacağına dair birçok ayet ve hadis vardır. Ancak bireyin başka bireylere karşı işlemiş olduğu suçlarda durum farklıdır. Bu hadis-i şerif'te Peygamber Efendimiz insanların başka bireylere karşı işlediği suçlarda herhangi bir affın söz konusu olmayacağını açıkça beyan etmiştir. Bunun sonucunda insanlar başka bireylere karşı suç işlemesi ihtimalini düşürmektedir.

İslam dininin suçu önlemeye yönelik vurguladığı önemli kavramlardan birisi de empati, yani karşıdaki bireyin yerine kendisini koyması durumudur. Bir suç işlendiğinde ortaya çıkacak olumsuzluğu hissederek veya fark ederek bunun olmasını önlemeye yönelik bu yaklaşımı şu hadisi şerifte görmek mümkündür: "Hiç kimse, kendisi için istediğini, başkası için de istemedikçe, gerçekten iman etmiş olmaz" (Buhârî, İmân 7).

Peygamber Efendimiz Mü'min kişinin muhakkak olarak kendisini başkasının yerine koyma şartını getirmektedir. Böylece meydana gelecek birçok haksızlık engellenmiş olmaktadir.

\section{4. İbadetler ve Suç İlișkisi}

Genel anlamda değerlendirildiğinde İslam dininde ibadetlerin insan davranışlan ve toplumsal ilişkilerde kötülüklerden uzak tutma anlamında önemli bir etkisi söz konusudur. Bu anlamda değerlendirildiğinde Kuranı Kerim'de "Namaz, taşkınlıktan ve kötülükten alakoyar." (Ankebut/45) ayeti bu duruma işaret etmektedir. Buna paralel olarak namaz kıldığ 1 halde, namazın insani ve toplumsal ilișkileri düzenleme -iyilik yapma- işlevini yerine getirmemeleri (iyilik yapmaya engel olmak) (Mâûn/7), yani toplumsal dayanışmaya katkı sunmamaları, yerilen bir davranış olarak değerlendirilmektedir. 
Cemaat ve grup bilinci kazandırmaya yönelik "birlikte ibadet" etme neticesinde toplumsal ilişkilere zarar verecek davranışların önüne geçilebilme ihtimali söz konusu olabilmektedir (Okumuş, 2005).

Hac ibadeti de insanların tekrar suç işlemesini engelleyici en önemli faktörlerden birisidir. Hacca giden kişiler Arafat'ta dua edip günahlarından af dilerler ve kendilerini hac dönüşünde önceki yaşamına göre daha masum duygulara sahip olurlar. Toplum içerisinde de bu kişilere "hacı" sıfatı verildiği için hacca giden insanlar tekrar suç işlemede iki yönden engel ile karşılaşırlar. Birincisi, hacının edinmiş olduğu masumluk ve temizlenmiş olma duyguları, ikincisi de toplum içinde "hacı" sıfatını edinmiş olması nedeni ile karşı karşıya kaldığı toplum baskısıdır. Zira hacca giden bir insanlar suç işlediğinde, o kişi hacca gitmemiş insanlara göre daha fazla kınamalara maruz kalmaktadırlar. Bunu destekleyici nitelikte olmak üzere Türk toplumunda gündelik hayat içerisinde "Bir de hacı olacak, hacılığından utan" tarzı kalıp ifadeler bu ibadetin toplumsal işlevini yerine getirdiğinin göstergelerinden biri olarak değerlendirilebilir.

İslam dini açısından önemli ibadetlerden birisi olan zekât, kelime olarak "temizlemek" anlamına gelmektedir. Toplumsal açıdan bakıldığında zenginlerin kendi mallarından fakirlere yardım etmesi ile o toplum içerisinde var olan zengin fakir arasındaki fark azalmaktadır. Bu yönüyle değerlendirildiğinde özellikle maddi suçlarda azalmanın olmasına etki edecek bir faktör olarak değerlendirilebilir.

Empati yapma anlayışı üzere bina edilmiş olan oruç ibadeti ile bireyin içinde yaşamış olduğu toplumlardaki diğer fakir bireylerin durumunu anlamasına katkı sağlamaktadır. Hz.

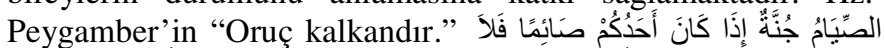
يruç bir kalkandır. Oruçlu kimse kötü söz söylemesin ve cahillik yapmasın -yani cahiliyet fiillerinden bir şey yapmasın. Eğer herhangi bir kimse kendisiyle dövüşmeye veya sövmeye girişirse, ona iki defa "Ben oruçluyum." desin. (Ebu Davûd) Hadis-i şerifi ile bireyin Ramazan ayında başlamak üzere yılın diğer tüm zamanları içerisinde kendisinin kötülüklere ve suç işlemeye karşı koruması şeklinde yorumlanması mümkündür. Ramazan ayında geçen günlerde de insanlar yine bu ayın kutsiyeti nedeni ile suç işlemeyi azaltmaktadır. Her yıl yayımlanan istatistiklerde de bu durum açıkça görülmektedir. Ramazan ayında trafik kazası tarzı suçlar yine aynı şekilde devam etmekte iken cinayet, yaralama, hırsızlık tarzı suçlarda azalma görülmektedir. Bunu destekleyici nitelikte olmak üzere Türk toplumunda gündelik hayat içerisinde "Oruç ağzl" kavramının kullanılması bu anlamda yine bu ibadetin toplum içerisindeki gücünü gösterir niteliktedir.

İslam dininde var olan ve "emr-i bi'l-m'arûf, nehy-i 'ani'lmünker" olarak bilinen iyiliği emretme ve kötülükten alıkoyma ayeti (Nahl, 90), toplumsal ilişkilerdeki düzensizlikleri önlemeye yönelik bir ifade olarak değerlendirilebilir.

\section{Toplumsal Tabakalaşma Bağlamında İslam'ın} Yaklaşımı

İslam'a göre toplumsal bozulma, toplumsal tabakalaşma perspektifine göre her toplumda kategorik olarak yer alan yönetici ve yönetilen sınıflarının ilişkisi dikkate alınarak değerlendirme yapılmaktadır."

Kuran-1 Kerim'de geçen şu ayet bize bu yaklaşımı açıkça göstermektedir:

"Biz bir topluluğu helak etmek istediğimiz zaman, onların önde gelenlerine emrederiz. Onlar da toplum içerisinde bozgunculuk yaparlar ve bizim sözümüz gerçekleşir. Onları da böylece yıkıp geçeriz." (İsrâ/16) Toplumun yönetici tabakasında suç işleme oranı arttıkça, toplumun geneli de bozulmaktadır. Zira aileden devlet yönetimine kadar toplum içerisindeki bütün sosyal kurumlarda yönetenler ve yönetilenler vardır. Sosyal kurumların yöneticilerinin sayısı az olsa bile, fazlaca suç işlemeleri durumunda, kendilerine tâbi olan bütün fertlere olumsuz yönde yansımaları meydana gelebileceği kabul edilmektedir. Örneğin ailede yönetici konumunda bulunan ebeveynin anne ile babanın suç işlemesi onların çocuklarını da etkilemektedir. Şirket yöneticisi suç işlerse şirket çalışanlarını olumsuz etkilemektedir. Sosyal kurumların en büyüğü olan devlette ise yöneticilerin suç işlemeleri o toplumda suça yönelimi artırabilmektedir. İslam dini iman, ibadet, muamelât (muameleler) ve ahlâk alanlarındaki prensiplerin uygulanmasını sağlamak, bunlarla ilgili emir ve yasakların ihlalini önlemek, ferdi ve içtimai hayatı bütün yönleriyle ıslah etmek maksadıyla gerek dünya gerekse ahiret hayatına yönelik olarak birtakım özendirici veya caydırıcı tedbirler almıştır. Bu tedbir ve müeyyidelerin tamamı ceza kavramının kapsamı içindedir (Akbulut, 2003: 167). İslâm, sadece meseleyi inanç boyutuyla sınırlı tutmamış, ibadet, güzel ahlak, güzel bir çevre, iyi bir eğitim ve ögretimi de inanç boyutuyla birlikte yürütmüştür. İslâm, temiz ve erdemli bir toplumun tesisi dolayısıyla suçun önlenmesinde ayrica aile müessesesinin mutlaka yaşatılmasını öngörmüştür (Erturhan, 2007: 142).

Suç ve suçluyu değerlendirme bağlamında ele alındığında İslam hukuku önünde imtiyazlı sınıf algısına rastlamak mümkün görünmemektedir. Bunun en çarpıcı örneği, Eşraf'tan bir kadının hırsızlık yapması sonucu Üsame b. Zeyd'in aracılık yapmaya çalışması olayıdır. Olay şu şekilde gerçekleşmiştir: Mahzûmî kabilesinden bir kadın hırsızlık yapmış ve cezalandırılması söz konusu olmuştur. Hz. Peygamber'in evlatlığının oğlu olan Üsame, kadın için arabuluculuk yapmaya çalışınca Peygamber Efendimiz mescitte hutbeye çıkarak "Sizden önceki kavimler, eşraftan birisi suç işlediğinde affedip zayıf durumda olanlar suç işlediğinde cezalandırdıkları için helak oldular. Muhammed kızı Fatıma bile hırsızlık yapsa onu cezalandırırım." buyurarak imtiyazlı sınıfa hiçbir şekilde iltimas geçilemeyeceğini açıkça ilan etmiştir.

\section{Suçun İnsanî (Ontolojik) Mahiyeti}

İslam'a göre yaratılışı gereği her insan suç işleme potansiyeline sahiptir. Kişinin içinde bulunduğu toplumsal yapı ve onun toplumsallaşma süreci suç ile ilişkisini belirleyen ana etmenlerdir. (Gründel, 1985: 80-87). Bu bağlamda şu hadis-i şerif konuya net bir çerçeve çizme özelliğine sahiptir: "Ademoğlunun tamamı hatalıdır. Hata yapanlar arasında en iyileri, hatasından tövbe edenlerdir." (Dârimî, Sunen, 3/1793) Hz. Peygamber'in bu hadisinde istisnasız her insanın hata yaptığı çok açıça beyan edilmektedir. Dolayısıyla insanlar, kategorik olarak suçlu ve suçsuz değil, suçunda israr edenler ile 
suçundan vazgeçenler olarak ele alınmaktadır. Aslında İslam'ın bu kategorik ayrımı suçta ısrar etmeme durumunu suç işlemeye göre öncelemesi bakımından altı çizilmesi gereken önemli bir tespittir.

İslam Dininde suç ile beraber ele alınan en önemli kavram "işlediği suçtan pişman olma", yani tövbe fonksiyonudur. Yani birey işlemiş olduğu suçtan pişmanlık duyduğunu belirtir ise, o kişi sanki o suçu hiç işlememiş kabul edilmek suretiyle hem psikolojik, hem de toplumsal entegrasyonu kolaylaştıracak şekilde masum kabul edilmektedir. Bunu açıç̧a şu hadisi şerifte görmek mümkündür: "İşlediği suçtan tövbe eden, sanki o suçu hiç işlememiş gibidir." (Taberânî, el-Mu'cemu'l-Kebîr 10281 no'lu hadis) Dolayısıyla İslam'a göre suç, insani bir özelliktir. Yukarıda verilen hadiste ifade edilen yaklaşım bir önceki başlıkta ele alınan toplumsal tabakalaşma ile ilişkili olarak değerlendirildiğinde ise, o toplumun en ileri geleni olan Peygamberlerin dahi istisna edilmemesi son derece dikkat çekici bir husustur. Yani Peygamberler de diğer insanlar gibi hata işleme özelliğine sahiptirler. Bu konuya Kuran'daki Abese suresinin iniş nedeni olan olayda Peygamber Efendimizin çevresindeki görme engelli bir birey olan İbn Ümmü Mektum ile olan ilişkisi örnek verilebilir. Söz konusu olayda Hz. Peygamber'in göstermiş olduğu davranış, Allahu Teâla tarafından kınanmaktadır. (Mâlik b. Enes, el-Muvatta', 2/283)

Ontolojik olarak suç işlemenin insan olmanın en temel karakteristiklerinden biri olduğu vurgulanmaktadır. Bir hadis-i şerifte şu şekilde geçmektedir: "Ĕ̆er siz günah işlemeseydiniz, Allah sizi helak eder ve yerinize günah işleyip, peşinden tevbe eden kullar yaratırdı." (Müslim, Tevbe, 9-11) Burada vurgu yapılan şey, suçun insanîliğidir.

Suçu işleyen kişi, toplumda bir stereotip olarak "suçlu" olarak damgalanmakta ve bu damgalanma kişinin aynı suça yeniden daha rahat yönelmesine zemin hazırlayıcı unsur olarak karşımıza çıkmaktadır. Çünkü toplumsal itibarı zedelenmiş bireyin koruyacak bir saygınlığının olmaması, ilk defa suç işleyen insana göre daha sonrasında yine suça yönelmesinde kolaylaştırıcı bir faktör olacaktır. $\mathrm{Bu}$ yönüyle değerlendirildiğinde İslam dinindeki tövbe etme mekanizmasının suçlu damgasını temizleyici özelliğinin ön plana çıkartılması Türk toplumu gibi geleneksel toplumlarda suçu yeniden işlemeyi önleyici bir işlev görebilir. Özellikle bu mekanizmanın yeniden suç işleme potansiyeli yüksek insanların yoğunluklu olarak bir arada bulunduğu hapishane ortamlarında daha aktif kullanılması suçu önlemeye yönelik önemli bir adım olarak değerlendirilebilir.

\section{Genel Değerlendirme ve Sonuç}

Dinin suç ve suçu önleme ilişkisi bir çok düşünürün ilgisini çekmiş ve bir çok araştırmaya konu olmuştur. Suçu önleme olgusu sadece idari düzenlemeler, adlî, hukukî ve kolluk kuvvetleri kullanılarak gerçekleştirilebilecek bir olgu değildir. Meselenin kültürel, toplumsal, zihinsel, geleneksel ve dinî kodları da dikkate alınarak multi-disipliner bir yaklaşımla ele alınmalıdır. Geleneksel özellikleri belirgin bir toplum yapısına sahip bir ülke olan Türkiye'de bu durum ayrıca özel bir önem arz etmektedir.

$\mathrm{Bu}$ bildiride Türk toplumunun değer, davranış ve yaşam tarzının şekillenmesinde önemli bir toplumsal kurum olarak
İslam dininin etkili olduğu ve bu dinî ve geleneksel kodların çözümlenmesi neticesinde ortaya çıkacak bilgilerin kullanılmasıyla suçu önlemeye yönelik oluşturulacak somut ve pratik stratejilere katkı sağlayacağı ifade edilmektedir.

Şu halde toplumun şekillenmesinde ve insan davranışının kontrol edilmesinde dinin aktif bir rol oynadığı görüşü, bazı sosyal bilimciler arasında büyük ölçüde kabul görmüştür. Örneğin Durkheim sosyal düzenin korunmasında ve ortak değerlerin oluşumunda dine temel bütünleştirici bir mekanizma rolü atfederken, Weber de dinin insanların dünyayı anlama biçimine ve bu anlam çerçevesi içerisinde pratik çözümler üretmesine önemli katkılar sağladığını ileri sürmektedir (Kızmaz, 2005: 1).

Evrensel bir olgu olan suç ve sempozyumumuzun konusu olan suçu önleme olgusunun aynı zamanda teritoryal etkisi önemlidir. $\mathrm{Bu}$ bağlamda suçun göreceliliği kavramından bahsetmek uygun olacaktır. Bir zaman diliminde suç olarak kabul edilen bir olgu, zamana göre suç özelliğini yitirebilmektedir. Bir toplumda suç olarak kabul edilen bir durum, bir başka toplum için meşru bir durum olarak görülebilir.

Batı ülkelerinde ve ülkemizde yapılan araştırma sonuçlarına ve çoğunluk sosyal bilimciye göre dinî ve ahlâkî değerler suç önlemede caydırıcı bir role sahiptir. $\mathrm{Bu}$ nedenle, insanların yaşadıkları ruhî boşluk ve bunalımlardan hareketle suça yönelmelerini önlemek amaciyla din ve ahlâk değerlerinden oluşan manevî değerlerin kazandırılması yönünde toplumu bilgilendirici ve eğitici çalışılmalar yapılması önem arz etmektedir.

Batı'da ve Türkiye'de yapılan birçok çalışmada ibadet ile suç işleme arasında yakın bir ilişki olduğu ifade edilmektedir. (Certel, 2008; Özdemir, 2006; Peker, 1987; Peker, 1990; Peker, 1994) Bu bağlamda suç ile ilgili istatistiksel veriler incelendiğinde Ramazan ayında birçok suç türünde önemli bir azalmanın meydana geldiği görülmektedir. Aynı şekilde dini ritüellere düzenli katılım gösterenler arasında suç işleme oranının bulunduğu toplumuna göre daha az oranda olduğu da görülmektedir.

İslam dininde insanın işlediği suçları ve yaptığı kötü davranışları gözetleyen ve aynı zamanda bunları kayıt altına alan bir meleğin bulunduğu inancı ve günlük namazların sonunda onun varlığını sembolik olarak hatırlatılan (selam uygulaması) inanan insanların suç işlemesini önleyici bir işlev görmektedir. Genel anlamda İslam dini örneğinde suç işleme ile dindarlık arasında ters bir orantısal ilişkinin olduğunu ifade etmek mümkündür.

\section{Kaynaklar}

Akbulut, İlhan, İslam Hukukunda Suçlar ve Cezalar, Ankara Üniversitesi Hukuk Fakültesi Dergisi, C.52. S.1, S.167-181.

Erturhan, Sabri İslâm Hukukunda Suçla Mücadele Yöntemleri, İslam Hukuku Araştırmaları Dergisi, S 9, 2007, S. 101-142.

İncil, Tevrat, Yaratılıș IV, 1-5; Müjde Yay., İstanbul 2004.

Kızmaz, Zahir, (2005), "Din ve Suçluluk: Suç Teorileri Açısından Kuramsal Bir Yaklaşım”, Fırat Üniversitesi Sosyal Bilimler Dergisi, c. 15, sy. 1, Elazı $\breve{g}$.

Buhari, Rikak, 48, Beyrut, 1998.

Dârimî, Sunen, 3/1793, Beyrut 1995. 
Taberânî, el-Mu'cemu'l-Kebîr 10281 no'lu hadis, Beyrut, 1992

Mâlik b. Enes, el-Muvatta', 2/283, Medine, 1985

Gründel, Johannes, Schuld und Versöhnung, MathiasGrünewald Verlag, Mainz, 1985.

Halife, Abdullah H. M., Islam'da Suç Eğilimine Karşı Koruyucu Bir Mekanizma Olarak Dindarlık, İslâmî Sosyal Bilimler Dergisi, 9-20, İstanbul, 1994.

Okumuş, Ejder, (2005), Çocuk Suçluluğunun Önlenmesi ve İslâm, İslâmiyât, c. 8, Ankara.

Özdemir, Şuayip, Cezaevlerinde Din Eğitimi, Arı Sanat Yayınevi, İstanbul, 2006.

Peker, Hüseyin, Suçlularda Dini Davranışlar, (Yayınlanmamış Doç. Tezi), Samsun, 1987.

Peker, Hüseyin, Suçlularda Dini Davranışlar, 19 Mayıs Üniv. İlahiyat Fak. Dergisi, 93-123, 1990.

Peker, Hüseyin, 99 Çocuk ve Suç, Çocuk Vakfı Yayınları, İstanbul, 1994. 